\title{
A Case of Primary Heart Sarcoma with Acute Cardiac Tamponade
}

\author{
Hayase Shisa, M.D.,* Hiroshi Yamagiwa, M.D., * \\ Masanobu Ozaki, M.D., ** and Kiyoshi Murata, M.D.**
}

DRIMARY myxomas, fibromyxomas and fibromyxosarcomas of the heart have been reported by several authors. ${ }^{1,2)}$,

In our case, the tumors of the heart showed various appearances, for example, fibromyxoma, fibromyxosarcoma and liposarcoma. It was polypoid and involved the pulmonary valves and the adjacent endocardium and extended also along the major pulmonary arteries and further smaller branches. The tumor metastasized to the left ventricle and left adrenal.

\section{Case RePort}

Clinical history: A 17-year-old Japanese school girl was admitted to Ise General Hospital on September 22, 1965, with chief complaints of palpitation and left upper abdominal pain. Nothing to describe in family history. When she coughed whooping cough at the age of 4 , she was pointed out a congenital heart disease (no descriptive details available), although at that time she was asymptomatic.

During her primary school days, she complained occasionally of palpitation and dyspnea when walking but she did not consult a physician and had never been treated.

About 2 years ago, she was confined to bed for 2 weeks and diagnosed as pleurisy, and after 3 weeks, she improved apparently.

Eighteen days prior to death (11 days before admission), she had a dull pain at left upper abdomen, but without nausea and diarrhea. Ten days prior to death, she had palpitation, epigastralgia, general fatigue and anorexia.

On admission (7 days prior to death), she complained of precordial oppression, coughs and lumbago.

Physical examination revealed a well-developed young female, $157 \mathrm{~cm}$. tall, $38 \mathrm{Kg}$. in weight, with blood pressure in the right arm of $110 / 80$. The pulse was 80 , regular and of good tension. The face was pale and slightly edematous, but no edema on pretibial region. There was no cyanosis, dyspnea, orthopnca, or clubbing.

Examination revealed cardiac enlargement and soft localized systolic blowing murmur at the pulmonic area and Graham's diastolic murmur to the left of the

* From the First Department of Pathology (Prof. K. Izutsu), Mie Prefectural University School of Medicine, Tsu.

** Department of Internal Medicine, Ise General Hospital, Ise.

Received for publication November 21, 1966. 
sternum in the fourth interspace was heard. There was no split and accentuation of the second sound at the pulmonic area. A chest X-ray showed an enlargement

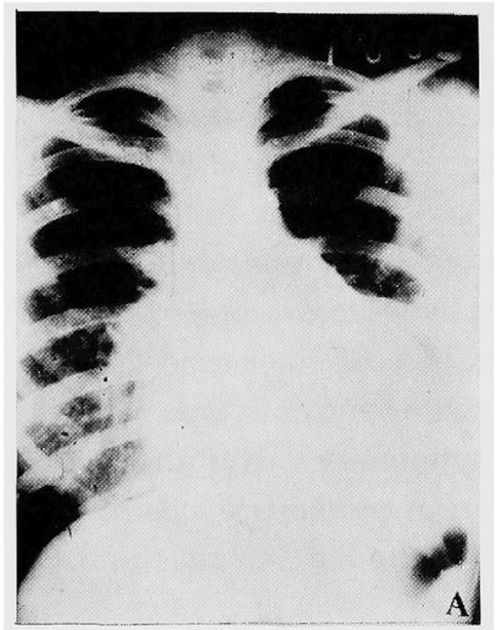

Fig. 1 (A). Ghest X-ray film taken few hours before death, showing enlargement of left ventricle.

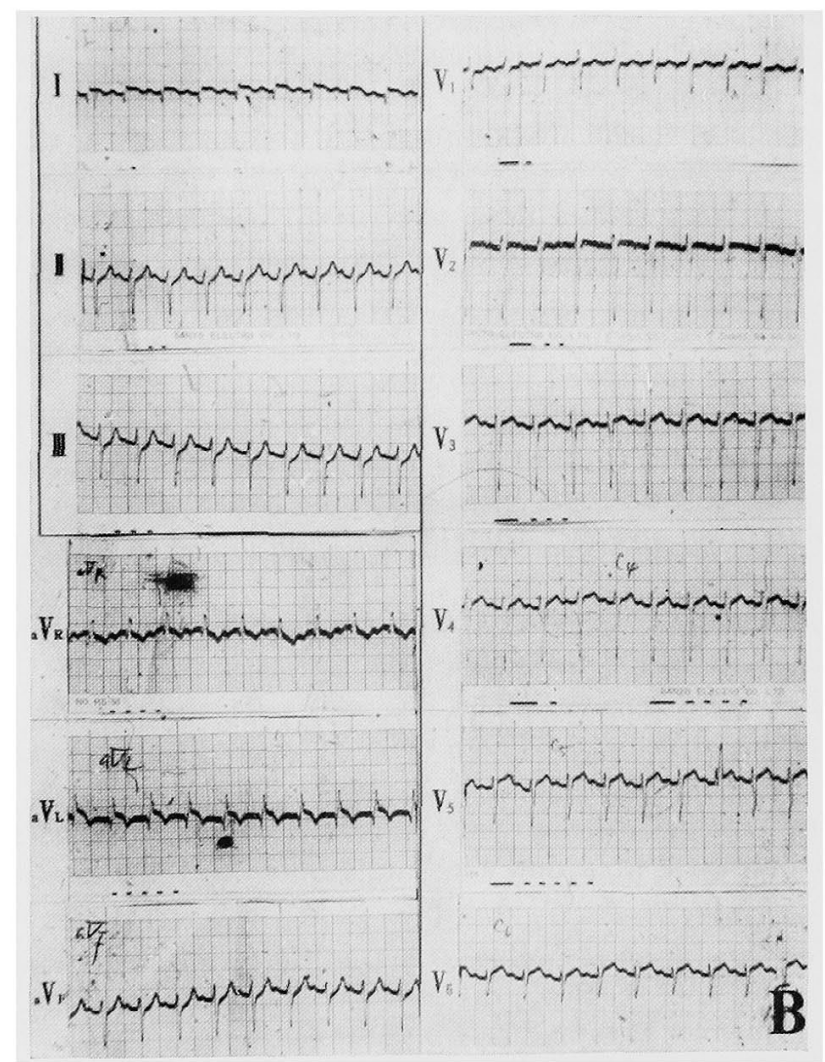

Fig. 2 (B). Electrocardiograms taken few hours before death. 
of both ventricles, especially, of the left one (Fig. 1). The E.G.G. showed rghit axis deviation and $S$ pattern in all the chest leads $V_{1-6}$. The lungs were normal by percussion and auscultation.

On the 5th hospital day, she complained of lumbago, and left upper abdominal pain. On the 7 th day she complained of precordial oppression, palpitation, nausea and dyspnea. Next day, her left abdominal pain aggravated extremely and pallor of face, dilatation of jugular vein, sweating and painful expression persisted until her sudden death on the 8th hospital day.

The E.C.G. on the 8th hospital day showed tachycardia, hypertrophy of the right ventricle, inverted $T$ waves and elevated $S T$ segements in Lead $a V_{R}$, and depressed ST segements in lead $\mathrm{aV}_{\mathrm{F}}$ (Fig. 2).

Laboratory data at the admission: The red cell count was 5.8 millions per mm. ${ }^{3}$; hemoglobin was $108 \%$ (Sahli); the white cell count was 13,800 per mm. ${ }^{3}$; sedimentation rate was $2 \mathrm{~mm}$. per hour. The urine showed $30-100 \mathrm{mg} . / 100 \mathrm{ml}$. of protein and showed negative about bile and sugar. Sediment was 1 plus reaction of red cells, 2 plus reaction of white cells. The total serum protein was $6.7 \%$, S-GOT 30 unit and S-GPT 22 unit. Serum electrolytes comprized sodium 130 mEq./L. potassium $3.0 \mathrm{mEq} / \mathrm{L}$. chloride $102 \mathrm{mEq} . / \mathrm{L}$. and calcium $4.6 \mathrm{mEq} . / \mathrm{L}$. The stool gave 1 plus reaction with benzidin.

The major finding at autopsy: Cyanosis was revealed on the face and trunk. There was no edema of the subcutaneous tissue of the chest and both ankles. Both the pleural cavities were empty. The left lung was attached by dense, fibrous bands to parietal pleural surfaces. The pericardial sac contained $550 \mathrm{ml}$. of blood.

Heart: It weighed $315 \mathrm{Gm}$. The subepicardial fat was excessive and edematous in appearance. In the left ventricular surface, bilobular, dark-red, partially yellow-white, soft pigeon-egg-sized tumor with focal hemorrhages was observed
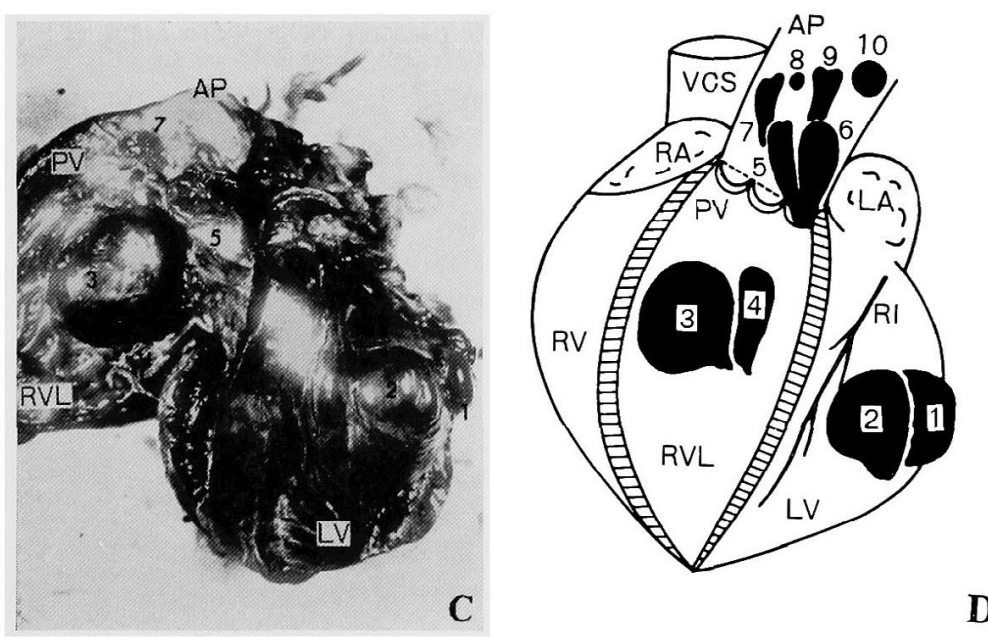

Figs. $3(\mathrm{C})$ and $4(\mathrm{D})$. Gross appearance and schematic representation of the cardiac tumors.: Hemorrhagic area (2) on left ventricular tumor is the site of bleeding which resulted in cardiac tamponade.

VGS: superior vena cava, RA: right auricle, RVL : right ventricular cavity, PV: pulmonary semilunar valve, PA: pulmonary artery, LA: left auricle, LV : left ventricle, RI : descending branch of left coronary artery. 
(Figs. 3 and 4-1,2). This tumor penetrated heart muscles and formed multiple villous processes in left ventricular cavity. In the right ventricular cavity, 4 myxomatous polypoid tumors were observed on the posterior wall (Figs. 3 and 4-3,4,5,6). Two of them (Figs. 3 and 4-3,4) were walnut and little finger's head sized, yellowish-white translucent, elastic soft and the largest one infiltrated into the papillary muscles and myocardium. The other 2 tumors (Figs. 3 and 4-5,6) formed myxomatous masses attached to regions just under the pulmonary valve orifice and hung into the pulmonary trunk and, with thickening of the pulmonary valves, almost occluded it. The pulmonary arterial wall was thickened covered with a layer of semitransparent soft gelatinous material of varying thickness (Fig. 5). The material extended through the pulmonary valve into both the branches of the pulmonary trunk, almost occluding the vessel. In the pulmonary trunk, 4 myxomatous polypoid tumors were attached by a short stalk to the posterior wall at points about $2 \mathrm{~cm}$. above the pulmonary valve orifice. The largest tumor was roughly pear-shaped, little-finger's head sized (Figs. 3 and 4-7) and the smallest one was egg-shaped, soy bean sized (Fig. 4-8). The surfaces of all the polypoid masses were smooth, glistening, pale-white, and semitransparent, except one which was dark-red, partially yellow-white soft tumor with focal hemorrhages, and resembled the left ventricular tumors (Fig. 4-10).

Around the left adrenal, there was hen's egg sized coagulation of the blood, which involved the cortex. This mass also contained a partially yellow-white and dark-red soft tissue which resembled the left ventricular tumors.

Microscopic findings: Myxomatous polypoid tumors of the right ventricular cavity and pulmonary trunk consisted of a great excess of mucinous ground substance over the cellular element (Figs. 3 and 4-5,6,7,8,9). The substance was faintly eosinophilic, amorphous, fine fibrillar material. Mucicarmin and PAS stain were positive. The cellular element was large stellate cells or spindle cells typical of myxomatous tissue. Some lymphocytes and plasma cells were seen (Fig. 6). In

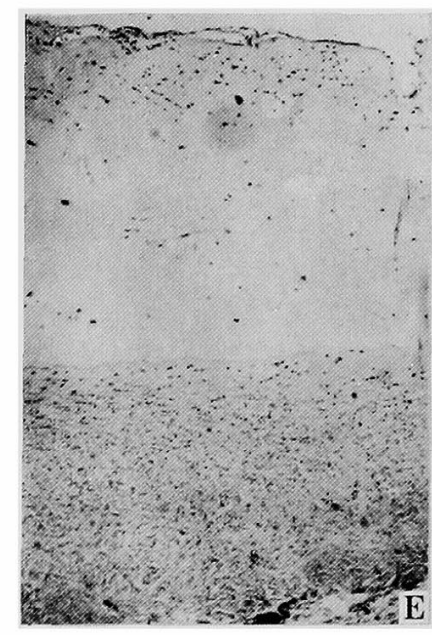

Fig. $5(\mathrm{E})$. Wall of the pulmonary artery, showing thickening of intima by myxomatous stroma containing tumor cells and lymphocytes. H. \& E. stain. $\times 80$.

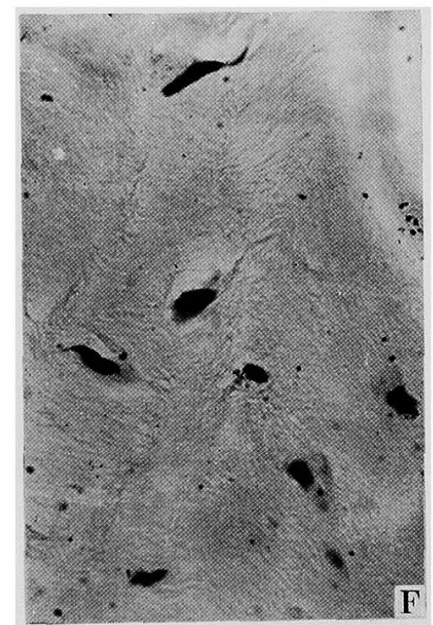

Fig. $6(\mathrm{~F})$. High power detail of myxomatous portion, showing round and spindle-shaped cells scattered in mucoid matrix. H. \& E. stain. $\times 260$. 


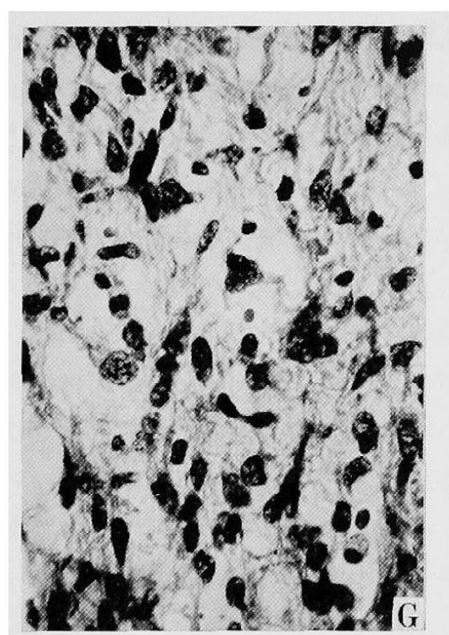

Fig. $7(G)$. High power detail of fibromyxosarcomatous portion. Cells are numerous and varied in size and shape. Some of them are spindle-shaped, stellate, round or oval. H. \& E. stain. $\times 260$.

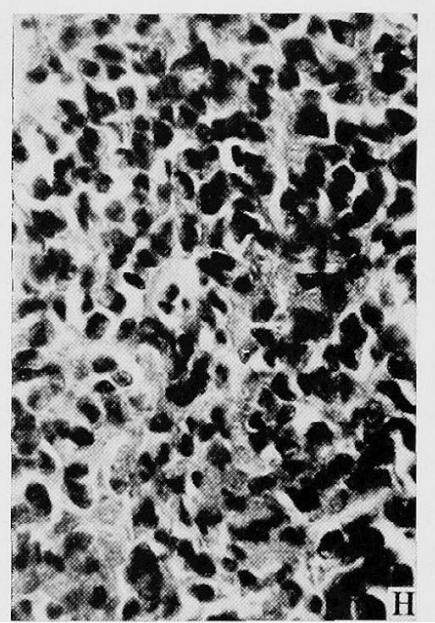

Fig. $8(\mathrm{H})$. High power detail of undifferentiated fibromyxosarcomatous portion. Tumor cells are more numerous, massive and varied greatly in size and shape. H. \& E. stain. $\times 260$.

the pulmonary trunk and arteries, the intima was thickened by the pseudomyxomatous or myxomatous stroma and were infiltrated with lymphocytes and tumor cells of the type already described. The histological feature of the other tumors of the right ventricular cavity as shown in Figs. 3 and 4-3,4, was differentiated fibromyxosarcoma (Fig. 7). Namely, the cells were more numerous and varied greatly in size and shape. Some of the cells were stellate or spindle-shaped with long processes and others were round or oval. Lymphocytic infiltration was present. The multiple villous tumors of the left ventricular cavity, the tumor of the left ventricular wall (Figs. 3 and 4-1,2), the one polypoid tumor of the pulmonary trunk (Fig. 4-10) and the left adrenal metastasis were less differentiated. The tumor cells were more densely packed and varied greatly in size and shape. In some regions, several fat granules were demonstrated in the cytoplasm of the tumor cells by Sudan III stain (Fig. 8).

\section{Comment}

In the present case, tumors of the left ventricle and left adrenal showed same histological features, and they were undifferentiated. While, those of the right ventricle, pulmonary valve and pulmonary arteries had more differentiated appearances. The latter was the primary tumor of fibromyxoma type, and became anaplastic to form metastases. When malignant tumor metastasizes to the heart, the primary invasion occurs in the myocardium and spreads into the endocardium and epicardium. The tumors developing from the endocardium should be considered as primary, in general. Primary 
tumors of the heart are not common. ${ }^{3)-5}$ Most of them develop from the left side of the heart. ${ }^{6}$. From the endocardium, myxoma, fibroma and fibromyxoma occur frequently compared with other types of tumors. Myxoma constitutes about $50 \%$ of the primary heart tumors; $75 \%$ of them arise from left atrium, $25 \%$ from right atrium. Ten cases of the ventricular myxoma have been reported so far. ${ }^{71}$

Haythorn $^{81}$ in 1941, reported a case of fibromyxosarcoma developing from the pulmonary trunk. The tumor showed multiple polypoid shape on the broad base just above the pulmonary valve and spread along the pulmonary arteries. Martin ${ }^{9}$ in 1939, described a polypoid tumor of pulmonary valve, which spread to adjacent endocardium and to pulmonary arteries. Microscopically, the case was polymorphous cell sarcoma. Gross ${ }^{10)}$ in 1941, developed a concept of fetal endocarditis on the still-born and newborn infants. In infants, heart, the red gelatinous (jelly-like) material simultating broadbased, smooth vegetations constitutes the remains of a myxomatous mesenchymal tissue and cannot be regarded as organizing vegetations. True residua of inflammation are never present. He considered these structures to be remnants of jelly-like material which makes up the original endocardial cushions. Such structures may persist and eventually become organized, giving rise to either so-called valvular myxoma or fibroma.

In our case, congenital heart disease ${ }^{11)}$ was pointed out at the age of 4 . We have been unable to confirm what was the congenital heart disease, however, it is conceivable that congenital valvular change ${ }^{12)}$ (fetal endocarditis?) existed at that time. We diagnosed our case to be fibromyxosarcoma with metastases to the left ventricle and left adrenal, which developed from the pulmonary valve or adjacent region to it, spreading to endocardium and pulmonary arteries.

Carcinoids ${ }^{13), 14)}$ and pheochromocytomas develop fibrosis ${ }^{15)}$ or hyperplasia of endocardium of the right ventricle and intima of the pulmonary arteries. Serotonin secreted by these tumors causes the changes described above, and this substance is decomposed by monoamine-oxidase in the lung. ${ }^{161-19}$ The hyperplasia of the intima of the pulmonary arteries in this case consists of neither simple fibrosis nor hyperplasia but infiltration of the tumor cells.

\section{Summary}

In the present case, tumors originated from endocardium just under the pulmonary valve orifice. They were polypoid and extended along the pulmonary trunk to the right and left pulmonary arteries, and metastasized to 
the left ventricle and left adrenal. Histologically, they consisted of fibromyxoma, fibromyxosarcoma, and liposarcoma. Finally, the patient died from acute cardiac tamponade caused by the bleeding from the left ventricular metastatic lesion.

\section{REFERENCES}

1. Prichard, R. W.: Arch. Path. 51 : 98, 1958.

2. Saphir, O.: Pathology of the Heart (2nd ed.), Charles C. Thomas Co., Spring Field, p. 857, 1960.

3. Kahrs, T. : Acta Path. Microbiol. Scand. 33: 151, 1953.

4. Ito, Y.: J. Jap. Soc. Intern. Med. : 52: 1235, 1964.

5. Abott, O. A. : Ann. Surg. $155: 855,1962$.

6. Sakauchi, G., et al.: J. Ther. (Tokyo) $46: 825,1964$.

7. Crummy, A. B. and Hipona, F. A.: Brit. J. Radiol. $37: 468,1964$.

8. Haythorn, S. R., Ray, W. D., and Wolf, R. A. : Am. J. Path. 17: 261, 1941.

9. Martin, W. C. and Mucciolo, P. : Am. Heart J. 17: 728, 1939.

10. Gross, P.: Arch. Path. 31: 163, 1941.

11. Raftery, E. B., Ahmed, S., and Brainbridge, M. V.: Brit. Heart J. 28 : 287, 1966.

12. Rona, G., et al.: Am. J. Cardiol. 12: 869, 1963.

13. Scenckloth, R. E., Page, I. H., and Cororan, A. C.: Circulation 19: 766, 1959.

14. Schweizer, W., Gloor, F., and Bertrab, R. V.: Circulation $19: 253,1964$.

15. Granford, M. A. : Am. Heart J. $66: 273,1963$.

16. Ahmed, F. S. and Harrison, G. V.: J. Path. Bacteriol. 87 : 325, 1964.

17. Birkenhäger, J. G.: Acta Med. Scand. 174: 621, 1963.

18. Levine, R.J., et al.: J.A.M.A. 186: 905, 1963.

19. Page, I. H. and Cocoran, A. C.: Circulation 19: 366, 1959. 